\title{
6-(N,N)-(Dimethylamino)fulvene: A Potential Precursor for a New Class of Fingermark Detection Reagents for Paper Surfaces
}

\author{
Jason M. Wells, ${ }^{a}$ Zachary Parsons, ${ }^{a}$ Renee Jelly, ${ }^{a} \dagger$ Alan D. Payne ${ }^{\mathrm{a}}$ and Simon W. Lewis ${ }^{\mathrm{a}, \mathrm{b}^{*}}$ \\ ${ }^{a}$ School of Molecular and Life Sciences, Curtin University, GPO Box U1987, Perth, Western Australia 6845, Australia \\ Email: s.lewis@curtin.edu.au Tel: +61892662484 \\ ${ }^{b}$ Curtin Institute for Functional Molecules and Interfaces, Curtin University, GPO Box U1987, Perth, Western \\ Australia, 6845, Australia \\ tCurrent address: Western Australia Police Forensic Division, Forensic Building, Cnr Clayton St \& Centennial PI, Midland \\ Western Australia, 6056, Australia
}

The ability to detect latent fingermarks on porous surfaces, such as paper-based documents, is extremely important in resolving criminal cases. Detection methods that target amino acids present in latent fingermark deposits have achieved widespread use due to the binding of these acids to paper fibres resulting in a good representation of the fingermark. This communication is the first report of $6-(N, N$-dimethylamino)fulvene (DMAF) as a novel reagent for the detection of latent fingermarks on porous surfaces. Through observation of undergraduate students showing poor laboratory hygiene, we noted that exposure to DMAF leads to brown staining on the students' skin. We discovered that indeed it can develop latent fingermarks on paper surfaces as pale pink impressions, which are luminescent when illuminated at $505 \mathrm{~nm}$ and viewed through orange goggles. The procedure is simple, requiring treatment of the specimen with a solution of DMAF in hexane with subsequent heat treatment. Preliminary experiments indicate that DMAF is reacting with the amino acids present in the latent fingermark.

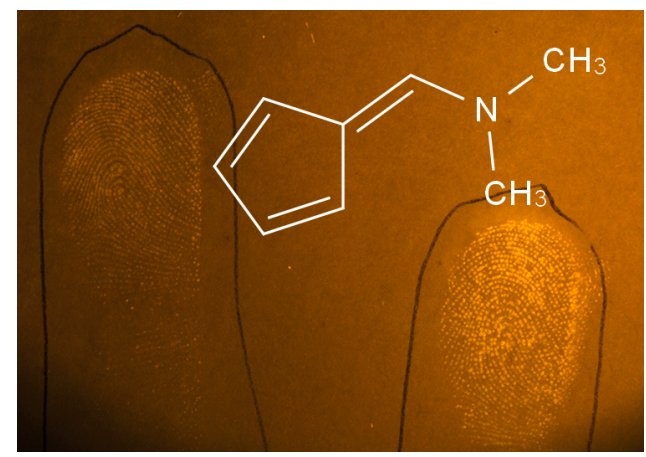

Keywords: Latent fingermarks; amino acids; paper surfaces; forensic science; photoluminescence

Fingermarks have long been used in police investigations and prosecutions not only as form of identification but also as a highly abundant form of trace evidence. ${ }^{1-4}$ Fingermarks can be used by a forensic investigator to determine whether a person was present at a scene and what objects they interacted with. Unlike other trace evidence such as fibres or hair, fingermarks generally only occur from primary contact and are very difficult to pass along by a third party for secondary transfer. ${ }^{4}$
Latent fingermarks are those formed by transfer of secretions of the skin onto a surface and are invisible without chemical or physical treatment. ${ }^{5}$ Both the chemical composition of a fingermark and the substrate upon which it has been deposited determines how it can be enhanced for visual examination. 3, 5-6 The amino acids present in skin secretions are highly relevant to fingermark enhancement on paper substrates and a number of amino acid-sensitive reagents are in routine operational use 3,5-10 The most commonly used is ninhydrin, and most operationally used reagents are based on its analogues. 5 , 7-8, 10-11 The visualisation of latent fingermarks on porous surfaces using these reagents can be considered to be the trace detection of amino acids where their spatial distribution needs to be retained for subsequent fingerprint analysis. As recently reported by Chadwick et al. current methods do not detect all available latent fingermarks. ${ }^{12}$ Fingerprint detection chemistry therefore shares with other areas of analytical chemistry the constant search for improved selectivity and sensitivity.

In recent times there have been studies into alternative sources for amino acid-sensitive reagents other than ninhydrin and its analogues, in particular those compounds that are known to stain skin. Genipin is extracted from Gardenia jaminoides and Genipa americana, and when it comes in contact with skin produces a violet stain. ${ }^{13-14}$ Another example, henna, is a skin and hair dye obtained from the leaves of Lawsonia inermis and has been in use for millennia. 5, 7-8, 10 The compound that causes this staining, lawsone, has been investigated as a fingermark reagent. ${ }^{8}$ Both lawsone and genipin react with amino acids in fingermark secretions to produce coloured ridge detail, which is also photoluminescent. ${ }^{5}$, $7-8,10,13$

In a similar fashion to lawsone and genipin, 6- $(\mathrm{N}, \mathrm{N}-$ dimethylamino)fulvene (DMAF) is a compound which was discovered to stain skin. An investigation into its potential use as a fingermark reagent was prompted after an undergraduate laboratory experiment at Curtin University, where it was used as a precursor to azulene. ${ }^{15}$ Students with poor laboratory hygiene had found that some of their skin had turned a brown colour after being exposed to the compound. Initial experiments were carried out using left over DMAF from the undergraduate lab. 


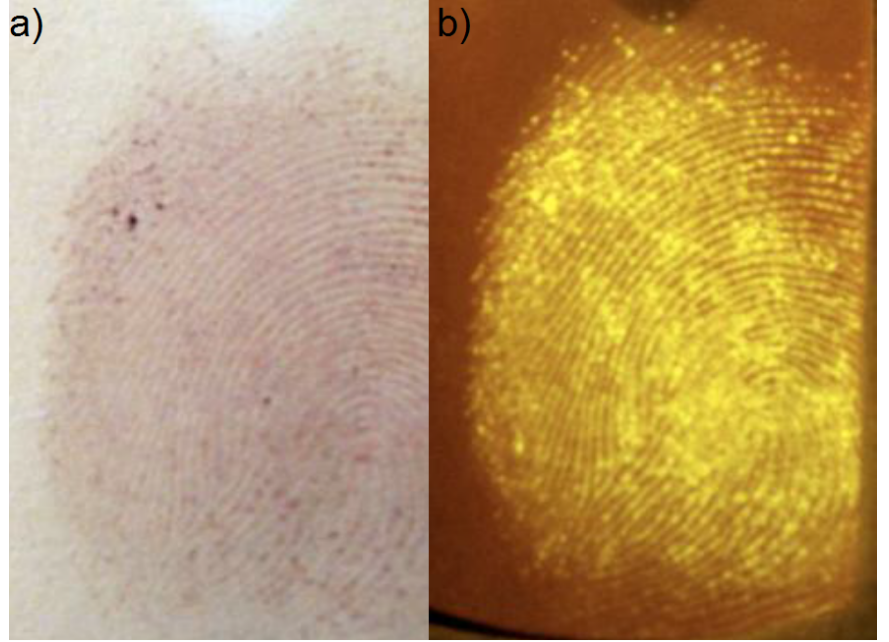

Figure 1: 6-(N,N)-(dimethylamino)fulvene treated latent fingermark. Images were taken with a Nikon D100 SLR (85 mm focal length, ISO 200): a) absorbance mode (shutter speed $1 / 30 \mathrm{~S}$ and aperture f9); b) photoluminescence mode with (shutter speed $1 \mathrm{~s}$, aperture f9).

A solution of this leftover DMAF in hexane was applied to a filter paper upon which a latent fingermark had been deposited. Once the hexane had evaporated the specimen was heated in an oven for a short period of time. The treated fingermarks appeared as faint pink ridges which exhibited luminescence when illuminated by a forensic light source at $505 \mathrm{~nm}$ and viewed through orange goggles (Rofin Polilight PL500; Figure 1).

Following this initial successful result, latent fingermarks were collected from a total of 6 donors. The donors' middle 3 fingers on each hand were pressed onto a piece of paper with squares marked on it, this was done 5 times sequentially to produce a 'depletion series' containing 5 sets of fingermarks. The depletion series allows a comparison of fingermarks with varying amounts of skin secretions. Fingermark treatment conditions are as follows unless otherwise stated. DMAF (80 $\mathrm{mg}$ ) was dissolved in hexane (100 $\mathrm{mL}$, Mallinckrodt Chemicals). Method development involved the variation of the concentration of the DMAF amount or different solvent combinations. Fingermark samples were dipped into the DMAF solution contained in a clean glass tray, ensuring that the paper had soaked through and all areas with fingermarks had been covered. These were then left to air dry in a fume cupboard, followed by heat treatment to facilitate the reaction. After heat treatment, pink ridge detail was evident under visible light. When excited by Rofin Polilight PL500 at $505 \mathrm{~nm}$ and viewed through an OG550 $550 \mathrm{~nm}$ camera filter, the fingermarks showed significant luminescence with good contrast.

A preliminary investigation between a laboratory oven and a standard heating press was investigated. The heating press gave much higher background development under visible light and under forensic Polilight. Samples which had been in the oven for 120 minutes had a reduced clarity when compared to the samples which had been in the oven for 30 and 60 minutes. Fingermarks which had been developed for 60 minutes or longer show a much higher level of background development causing parts of the prints to be barely visible.
DMAF dissolves in non-polar solvents, which is advantageous as polar solvents can cause the ink on documents to run preventing further document analysis. ${ }^{8,16}$ Solvents tested include hexane, petroleum spirits $40-60{ }^{\circ} \mathrm{C}$ (APS Chemicals), propylene glycol (Merck) and toluene (Sigma-Aldrich). DMAF readily dissolved in toluene, hexane and petroleum spirits; however, preparation in propylene glycol required additional light heating.

The toluene-based reagent caused the ink labels to run, ruining any documents. The petroleum spirits caused high background luminescence, obscuring any fingermarks. Propylene glycol showed some indications of fingermarks but very poor quality. Hexane produced the best quality fingermarks. Unlike other amino acid sensitive fingermark reagents, DMAF does not require a mixture of different solvents for development, making development solution preparation significantly easier. 8,16

Hexane was also compared to $3 \mathrm{M}^{\mathrm{TM}}$ Novec $^{\mathrm{TM}}$ Engineered Fluid HFE-7100, a solvent used to prepare other fingermark reagents and is the solvent of choice in Australian Police forensic laboratories due to its minimal dissolution of inks. ${ }^{17-18}$ The results were comparable as shown in Figure 2, but hexane remained the chosen solvent because of its much lower cost.

Investigations were also performed to determine optimum DMAF concentration. Figure 3 shows a significant increase in the background development, producing fingermarks which are difficult to visualise without image adjustment software. The lowest concentration of $20 \mathrm{mg} / 100 \mathrm{~mL}$ appeared to give the best contrast. However, further investigations indicated that a concentration in the range of 60-100 mg gave more consistent performance. Higher resolution images of fingermarks on paper developed with DMAF are presented in Figure 4.

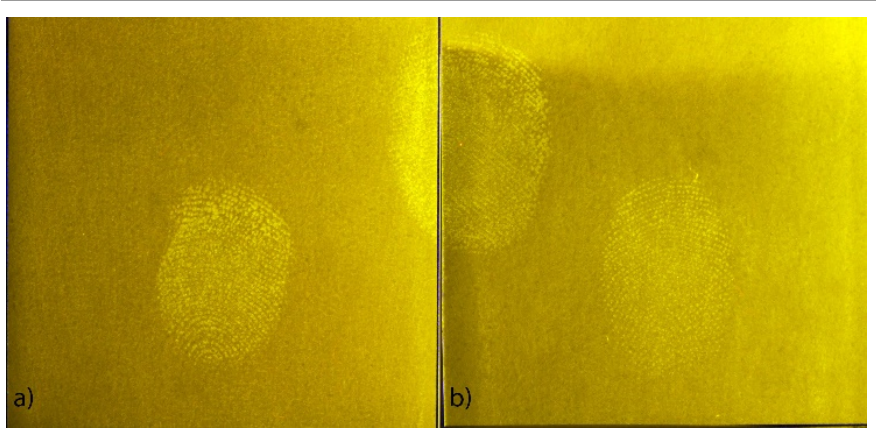

Figure 2: Comparison of HFE-7100 and Hexane when used as a carrier solvent. The fingermarks are from the same donor on the same hand, cut in half down the middle (a) HFE-7100 (b) hexane

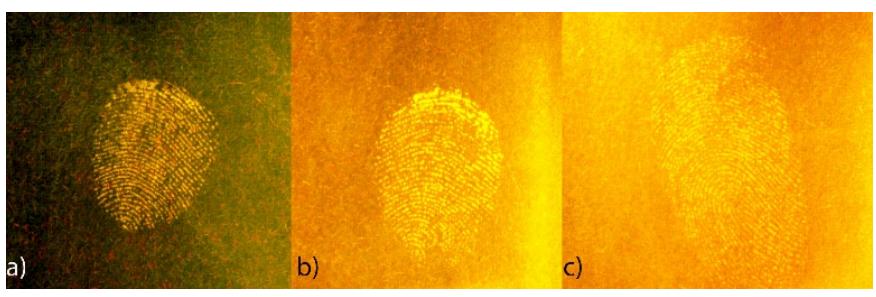

Figure 3: Fingermarks developed with varying concentrations of DMAF in $100 \mathrm{~mL}$ of hexane. The background luminescence greatly increases with the concentration (a) 20 $\mathrm{mg} / 100 \mathrm{~mL}$ (b) $80 \mathrm{mg} / 100 \mathrm{~mL}$ (c) $160 \mathrm{mg} / 100 \mathrm{~mL}$ 

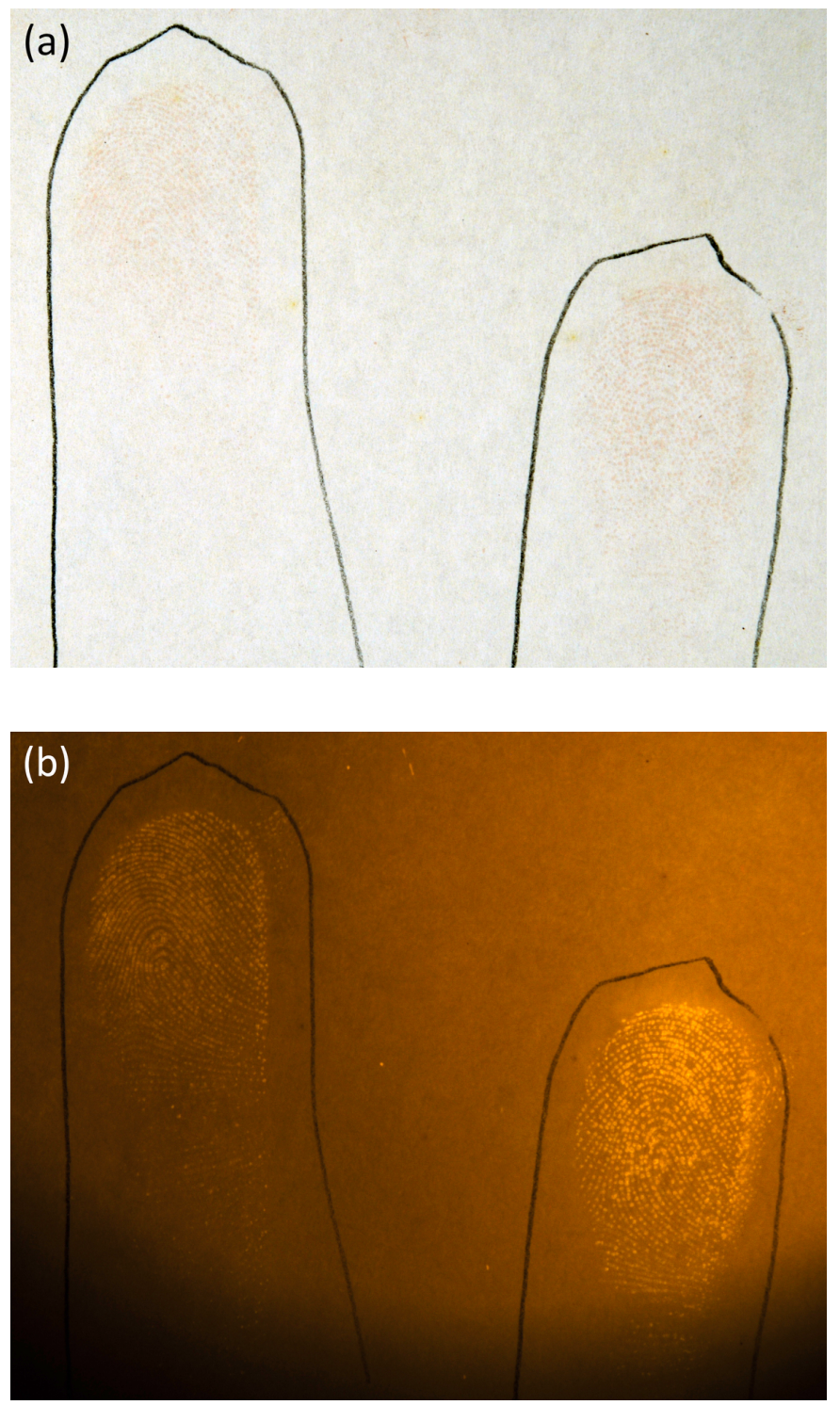

Figure 4: 6-(N,N)-(dimethylamino)fulvene treated latent fingermarks. Images were taken with a Nikon D300 SLR (60 mm focal length, ISO 200): a) absorbance mode (shutter speed $1 / 40$ s and aperture f8); b) photoluminescence mode with excitation using a Polilight PL 500 at $505 \mathrm{~nm}$ and viewed through a KV 550 filter,
(shutter speed $1 / 15 \mathrm{~s}$, aperture f8)

A preliminary investigation to confirm that DMAF reacts with amino acids was undertaken. 5, 10, 15, 20, $25 \mathrm{ng}$ per $10 \mu \mathrm{L}$ of two major amino acids found in sweat, 6,8 alanine and serine were spotted onto paper in $30 \mu \mathrm{L}$ aliquots and left to air dry. A "stacked" fingermarks from a single donor was also included for comparison, where the donor stacked all fingermarks from one hand on top of each other to produce a large amount of skin secretions in the one location. Once the spots were dry they were developed in DMAF solution. There was a visible increase in luminescence intensity compared with the water blank. Luminescence intensities of the treated amino acids spots and latent fingermarks were measured using a Cary Eclipse Fluorescence Spectrophotometer with fibre optic attachment (Varian, Mulgrave, Australia), at $580 \mathrm{~nm}$ with an excitation wavelength of $505 \mathrm{~nm}$ (Figure 5).

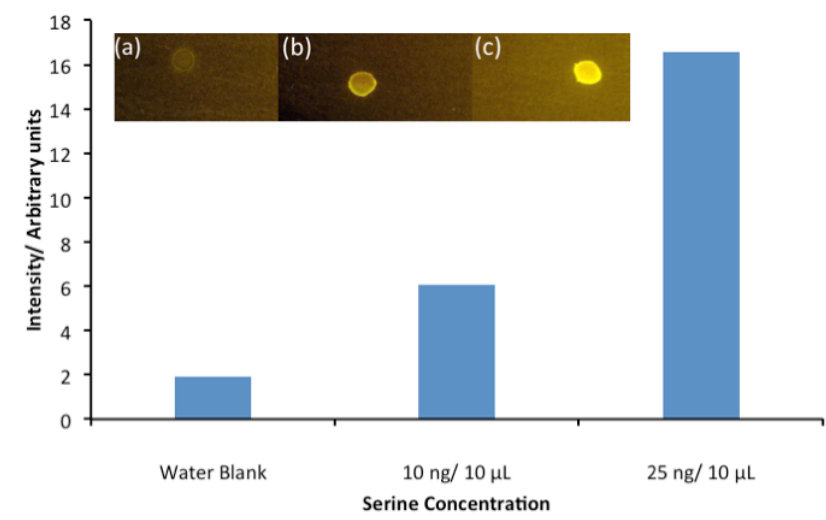

Figure 5: Luminescence intensity of amino acid spots on paper developed with DMAF $\left(\lambda_{\text {ex }}=505 \mathrm{~nm}, \lambda_{\text {em }}=580 \mathrm{~nm}\right.$ ) (a) water blank (b) $10 \mathrm{ng} / 10 \mu \mathrm{L}$ serine (c) $25 \mathrm{ng} / 10 \mu \mathrm{L}$ serine

Luminescence spectra of the treated amino acids spots and fingermark were collected over wavelength range 520-650 nm at an excitation wavelength of $505 \mathrm{~nm}$ (Figure 6). The spectra obtained from the alanine and serine treated spots has a maximum intensity at a wavelength of $580 \mathrm{~nm}$ while the stacked fingermark's maximum intensity is shifted slightly to the left at approximately $570 \mathrm{~nm}$. This shift in maximum intensity is also evident in similar amino acid tests with genipin. ${ }^{13}$ As secretions from the skin contain a mix of approximately 15 amino acids ${ }^{5-6}$ rather than just alanine and serine, it is possible that the reaction of the DMAF with individual amino acid species forms a series of unique products.

Scheme 1 shows a proposed reaction pathway for the reaction of $\mathrm{DMAF}^{19-21}$ with amino acids. The amino acid replaces the dimethylamine of DMAF followed by a condensation to give the cyclopenta[b]pyridine derivative. The amino acid side-chain is retained in the final product which could give rise to the maximum intensity shifts seen in Figure 6.

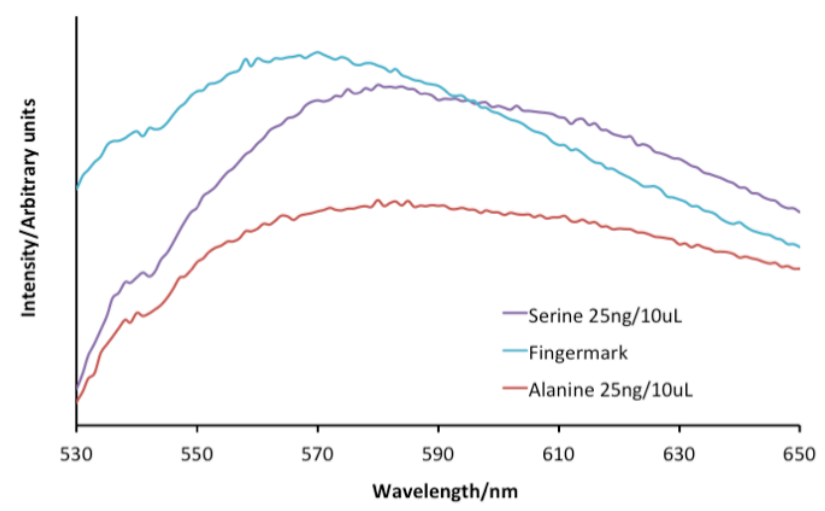

Figure 6: Fluorescence spectra of amino acid spots and a latent fingermark on paper developed with DMAF $\left(\lambda_{\text {ex }}=505 \mathrm{~nm}\right.$ ) 


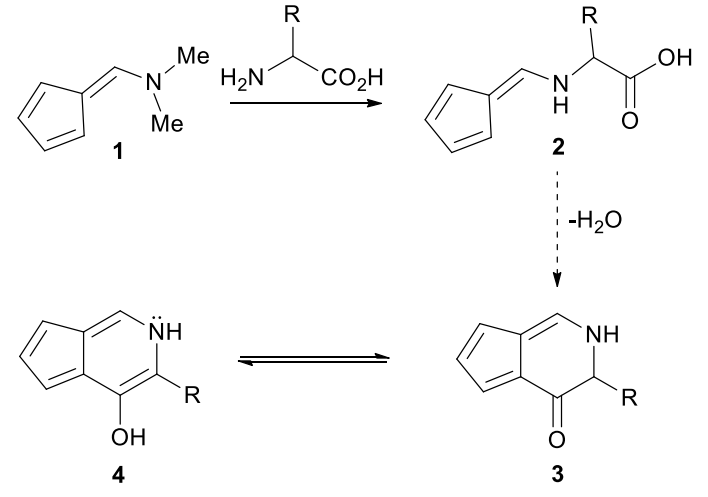

Scheme 1: Proposed reaction mechanism of DMAF with amino acids

This pathway is not confirmed and further investigation and isolation of products is required.

In conclusion DMAF has potential as a new fingermark development reagent that is soluble in common non-polar laboratory solvents without the need for any complex solvent mixtures. The use of non-polar solvents, such as hexane or HFE7100, enables the treatment of paper documents without damaging text present on the page. Further studies are required, as outlined by the International Fingerprint Research Group's Guidelines for the Assessment of Fingermark Detection Techniques ${ }^{22}$, to establish the suitability of DMAF for operational use. DMAF also represents a good "lead" compound for the synthesis of non-ninhydrin based fingermark reagents.

Renee Jelly was supported by a Curtin University Postgraduate Scholarship.

\section{Notes and references}

1. Kiely, T. F., Fingerprints. In Forensic Evidence, CRC Press: 2005; pp 339-387.

2. John, B.; David, S., History and Development of Fingerprinting. In Advances in Fingerprint Technology, Second Edition, CRC Press: 2001.

3. Champod, C.; Lennard, C.; Margot, P.; Stoilovic, M., Fingerprint Detection Techniques. In Fingerprints and Other Ridge Skin Impressions, CRC Press: 2004.

4. M.Houck, M.; Siegel, J. A., Fundamentals of Forensic Science. Elsevier: USA, 2010.

5. Jelly, R.; Patton, E. L. T.; Lennard, C.; Lewis, S. W.; Lim, K. F., The detection of latent fingermarks on porous surfaces using amino acid sensitive reagents: A review. Analytica Chimica Acta 2009, $652(1-2), 128-142$.

6. Girod, A.; Ramotowski, R.; Weyermann, C., Composition of fingermark residue: A qualitative and quantitative review. Forensic Science International 2012, 223, 10-24.

7. Robert, R., Amino Acid Reagents. In Lee and Gaensslen's Advances in Fingerprint Technology, Third Edition, CRC Press: 2012; pp 17-54.

8. Jelly, R.; Lewis, S. W.; Lennard, C.; Lim, K. F.; Almog, J., Lawsone: a novel reagent for the detection of latent fingermarks on paper surfaces. Chemical Communications 2008, (30), 3513-3515.
9. Wallace-Kunkel, C.; Lennard, C.; Stoilovic, M.; Roux, C., Optimisation and evaluation of 1,2-indanedione for use as a fingermark reagent and its application to real samples. Forensic Science International 2007, 168 (1), 14-26.

10. Joseph, A., Ninhydrin and Ninhydrin Analogues. In Lee and Gaensslen's Advances in Fingerprint Technology, Third Edition, CRC Press: 2012; pp 293-306.

11. Odén, S., Detection of Fingerprints by the Ninhydrin Reaction. Nature 1954, 173 (4401), 449.

12. Chadwick, S.; Moret, S.; Jayashanka, N.; Lennard, C.; Spindler, X.; Roux, C., Investigation of some of the factors influencing fingermark detection. Forensic Science International 2018, 289, 381-389.

13. Almog, J., Genipin-a novel fingerprint reagent with colorimetric and fluorogenic activity. Journal of Forensic Sciences 2004, 49 (2), 255-7.

14. Lennard, C., Fingerprint detection: future prospects. Australian Journal of Forensic Sciences 2007, 39 (2), 73-80.

15. Lemal, D., Synthesis of azulene, a blue hydrocarbon. Journal of chemical education 1988, 65 (10), 923.

16. Menzel, E. R., Fingerprint Detection with Lasers, Second Edition. Taylor \& Francis: 1999.

17. $3 \mathrm{M}$ Company $3 \mathrm{M}^{\mathrm{TM}}$ Novec $^{\mathrm{TM}}$ Engineered Fluid HFE-7100.

18. Stoilovic, M.; Lennard, C., Fingerprint Detection \& Enhancement. 6th ed.; National Centre for Forensic Studies: Canberra, 2012.

19. Fujikawa, S.; Fukui, Y.; Koga, K.; Iwashita, T.; Komura, H.; Nomoto, K., Structure of genipocyanin G1, a spontaneous reaction product between genipin and glycine. Tetrahedron Letters 1987, 28 (40), 4699-4700.

20. Touyama, R.; Inoue, K.; Takeda, Y.; Yatsuzuka, M.; Ikumoto, T.; Moritome, N.; Shingu, T.; Yokoi, T.; Inouye, H., Studies on the Blue Pigments Produced from Genipin and Methylamine. II .On the Formation Mechanisms of Brownish-Red Intermediates Leading to the Blue Pigment Formation. Chemical \& Pharmaceutical Bulletin 1994, 42 (8), 1571-1578.

21. Sanz, D.; Pérez-Torralba, M.; Alarcón, S. H.; Claramunt, R. M.; Foces-Foces, C.; Elguero, J., Tautomerism in the Solid State and in Solution of a Series of 6-Aminofulvene-1-aldimines. The Journal of Organic Chemistry 2002, 67 (5), 1462-1471.

22. International Fingerprint Research Group, Guidelines for the Assessment of Fingermark Detection Techniques. Journal of Forensic Identification 2014, 64, 174-200. 